\title{
'Cool and quiet' therapy for malignant hyperthermia following severe traumatic brain injury: A preliminary clinical approach
}

\author{
YU-HE LIU, ZHEN-DE SHANG, CHAO CHEN, NAN LU, QI-FENG LIU, MING LIU and JING YAN \\ Department of Neurosurgery, The 88th Hospital of PLA, Taian, Shandong 271000, P.R. China
}

Received February 13, 2014; Accepted October 21, 2014

DOI: $10.3892 /$ etm.2014.2130

\begin{abstract}
Malignant hyperthermia increases mortality and disability in patients with brain trauma. A clinical treatment for malignant hyperthermia following severe traumatic brain injury, termed 'cool and quiet' therapy by the authors of the current study, was investigated. Between June 2003 and June 2013, 110 consecutive patients with malignant hyperthermia following severe traumatic brain injury were treated using mild hypothermia $\left(35-36^{\circ} \mathrm{C}\right)$ associated with small doses of sedative and muscle relaxant. Physiological parameters and intracranial pressure were monitored, and the patients slowly rewarmed following the maintenance of mild hypothermia for 3-12 days. Consecutive patients who had undergone normothermia therapy were retrospectively analyzed as the control. In the mild hypothermia group, the recovery rate was $54.5 \%$, the mortality rate was $22.7 \%$, and the severe and mild disability rates were 11.8 and $10.9 \%$, respectively. The mortality rate of the patients, particularly that of patients with a Glasgow Coma Scale (GCS) score of between 3 and 5 differed significantly between the hypothermia group and the normothermia group $(\mathrm{P}<0.05)$. The mortality of patients with a GCS score of between 6 and 8 was not significantly different between the two groups $(\mathrm{P}>0.05)$. The therapy using mild hypothermia with a combination of sedative and muscle relaxant was beneficial in decreasing the mortality of patients with malignant hyperthermia following severe traumatic brain injury, particularly in patients with a GCS score within the range 3-5 on admission. The therapy was found to be safe, effective and convenient. However, rigorous clinical trials are required to provide evidence of the effectiveness of 'cool and quiet' therapy for hyperthermia.
\end{abstract}

Correspondence to: Dr Yu-He Liu, Department of Neurosurgery, The 88th Hospital of PLA, 6 Dongcun, Hongmen Road, Taian, Shandong 271000, P.R. China

E-mail: yuheliu123@yeah.net

Key words: traumatic brain injury, malignant hyperthermia, mild hypothermia, 'cool and quiet' therapy

\section{Introduction}

Malignant hyperthermia following severe traumatic brain injury occurs due to damage to the thermoregulatory centers, occurring within the first three days after head trauma, a time frame less likely for hyperthermia to be attributable to infectious causes (1). Previous studies have shown that malignant hyperthermia increases mortality and disability in patients with brain trauma (1-5). In brain damage such as stroke, hyperthermia acts through several mechanisms to exacerbate cerebral ischemia (1), including the increased release of neurotransmitters, excessive production of oxygen radicals, extensive blood-brain barrier breakdown, increased ischemic depolarizations in the focal ischemic penumbra, impaired recovery of energy metabolism, enhanced inhibition of protein kinases and worsening of cytoskeletal proteolysis $(6,7)$. Hyperthermia significantly increases the incidence of infection (1) and elevates the intracranial pressure, causing brain cell damage (4). Hyperthermia can increase the metabolism of the body, accelerate organ failure and affect the efficacy of neuroprotectant and thrombolytic therapy $(8,9)$. Therefore, the control of hyperthermia is necessary in the treatment of traumatic brain injury. Therapeutic hypothermia has become a focus of research in recent years.

Previous studies have shown that hypothermia can reduce the basal metabolic rate, the consumption of oxygen by brain cells $(5,10)$ and intracranial pressure, and protect the blood-brain barrier. Hypothermia has neuroprotective effects (11), which involve reduced extracellular glutamate release (12-14), limited calcium transfer (15), the reduction of free radicals $(12)$, the inhibition of nitric oxide $(16,17)$ and reduced brain metabolism. However, the lower the temperature, the greater the incidence of side-effects and complications (18), such as shivering, reduced electrolyte levels, dysregulated acid-base status, insulin resistance, kidney dysfunction, arrhythmia and impaired immune function. Currently, the temperature range of therapeutic hypothermia remains controversial (14). A number of studies have described the effects of moderate hypothermia $\left(32-35^{\circ} \mathrm{C}\right)$; however, due to the various complications (19), difficulties in temperature maintenance and damage following rewarming (20), the clinical application of hypothermia is limited. Certain studies have demonstrated that mild hypothermia can help to improve outcomes $(21,22)$ without clear explanation. Thus, it is essential to balance the maximum efficacy and minimum complications 
of therapeutic hypothermia. The aim of the present study was to investigate a new therapeutic hypothermia method known as 'cool and quiet' therapy for malignant hyperthermia in patients following severe traumatic brain injury

\section{Patients and methods}

Patient selection. A total of 110 consecutive patients in the 88th Hospital of PLA (Taian, China) with malignant hyperthermia following severe traumatic brain injury were enrolled from June 2003 to June 2013. The patients had a Glasgow Coma Scale (GCS) score of between 3 and 8 points, had spent $>6 \mathrm{~h}$ in a coma after injury, or experienced a deterioration of awareness following $>6 \mathrm{~h}$ in a coma within $24 \mathrm{~h}$ after injury. Cases with serious infections, dehydration fever, transfusion reactions, use of psychotropic inhibitors or clinical brain death (GCS $\leq 3$ and no brain-stem reflexes) were excluded. In addition, 110 cases that had undergone normothermia therapy, in which patients' temperatures were maintained between $36-37^{\circ} \mathrm{C}$, were retrospectively analyzed as the control. The present study was conducted according to the revised Declaration of Helsinki (2008 edition), and the approval of the ethical committee of the 88th Hospital of PLA was obtained. Written informed consent was provided by all participants prior to the study.

Patient assessment. Patients who met the entry criteria were examined by a continuous CT scan, and the GCS was determined based on ability of the patient to open their eyes, speak, and use their arms or legs. Temperature measurement methods were as follows: As there are numerous blood vessels around the rectum, which more sensitively reflect changes in body temperature, rectal temperature measurements were preferred. When using the retention enema, the temperatures of the patients were measured orally.

Treatment protocol. On the basis of actively treating the primary disease, all patients were treated with mild hypothermia $\left(35-36^{\circ} \mathrm{C}\right)$ in addition to small doses of sedative and muscle relaxant.

Basic treatment. On the basis of actively treating the primary trauma, patients with severe cerebral edema, extensive cerebral contusion and brainstem damage that were unconscious were treated with the programmed cooling therapy as soon as possible. It was maintained for 3-12 days, over the period at which trauma acute reactions and edema peak. The therapy was administered in combination with monitoring of the heart rate, blood pressure, breathing and pulse. The invasive intracranial pressure (ICP) of 40 patients was monitored during surgery or through a probe placed through a hole drilled in the skull (Fig. 1), with a Codman intracranial pressure monitor (Codman Neuro, Raynham, MA, USA; Fig. 2) and intracranial pressure sensor.

Mild hypothermia with physical methods. i) Hypothermia instrument such as an ice blanket. The efficacy of such a method was significant, and so was considered first. The body temperature was set to $35-36^{\circ} \mathrm{C}$ and the water temperature was set to $8-15^{\circ} \mathrm{C}$. The room temperature was maintained at $20-25^{\circ} \mathrm{C}$. When the body temperature was higher than the maximum of the set temperature, the water cycle started, which then took heat away and lowered the body temperature.

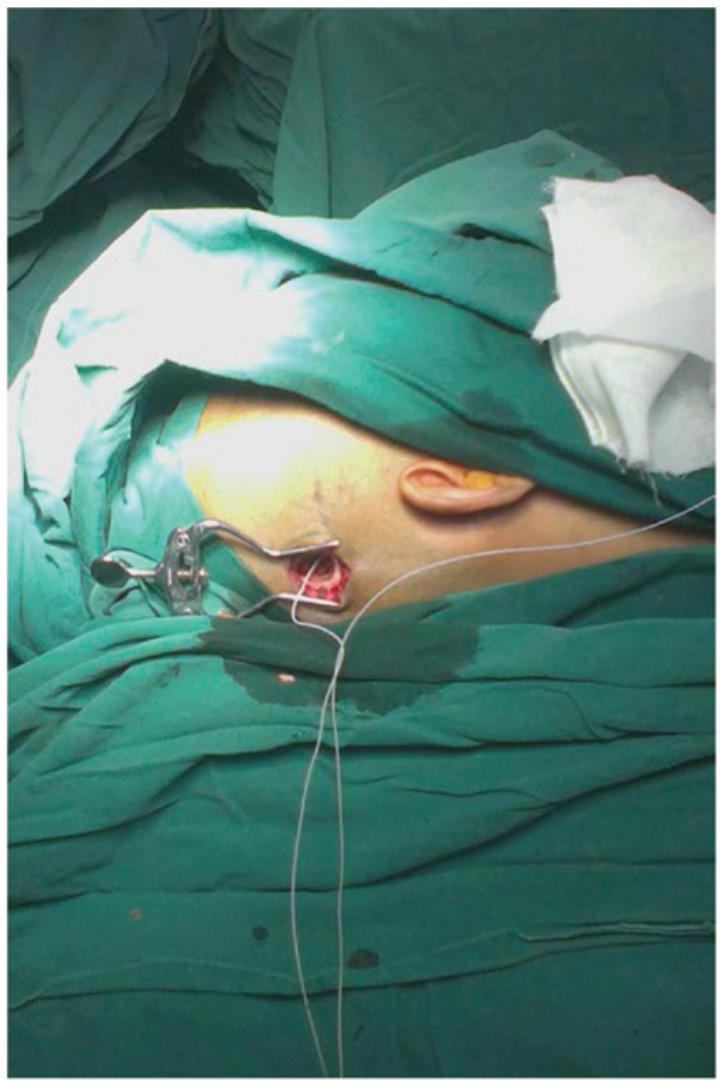

Figure 1. Intracranial pressure monitoring during surgery.

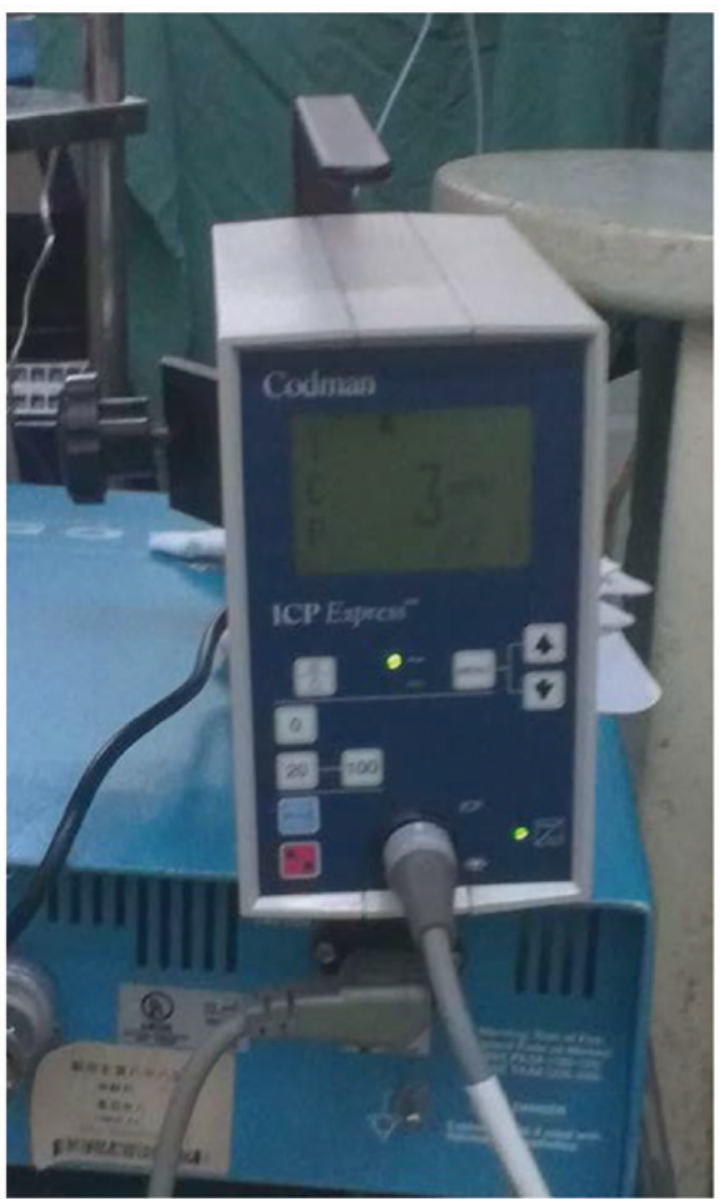

Figure 2. Codman intracranial pressure monitor. 
Table I. Clinical observations of the two types of therapy.

\begin{tabular}{lcccccc}
\hline \multirow{2}{*}{ Groups } & & \multicolumn{2}{c}{ Prior to treatment } & & \multicolumn{2}{c}{ Following treatment } \\
\cline { 3 - 4 } & Cases & $\mathrm{T}\left({ }^{\circ} \mathrm{C}\right)$ & GCS score & & $\mathrm{T}\left({ }^{\circ} \mathrm{C}\right)$ & GCS score \\
\hline Normothermia & 110 & $39.54 \pm 1.9$ & $5.7 \pm 2.1$ & & $37.37 \pm 1.2$ & $8.4 \pm 1.8$ \\
Mild hypothermia & 110 & $39.62 \pm 1.6$ & $5.5 \pm 1.9$ & & $37.73 \pm 1.6$ & $8.7 \pm 1.5$ \\
\hline
\end{tabular}

T, temperature; GCS, Glasgow Coma Scale.

ii) Simple body surface hypothermia. The patient's head (with the exception of the face) was put in an ice cap or ice tank, setting the temperature of the electronic ice cap at -2 to $+2^{\circ} \mathrm{C}$. Concurrently, ice salt or chemical ice bags wrapped in a towel were placed around both sides of the neck, armpits, groin and other parts of the body with large vessels. Patients, with the exception of those with brain herniation were given a retention enema with $500 \mathrm{ml}$ cold saline and $1 \mathrm{~g}$ aspirin for $30 \mathrm{~min}$. The temperature was measured again $30 \mathrm{~min}$ after the retention enema and the retention enema was repeated every 4-6 h. Through the above method, the temperature was maintained at $35-36^{\circ} \mathrm{C}$.

Sedative and muscle relaxant. To avoid shivering with skin reactions and to eliminate the acute stress reaction of the body to the internal and external environment, sedative and muscle relaxant administration was carried out simultaneously with hypothermia. Patients with increased intracranial pressure accompanied by restlessness, fever, convulsions and decerebrate rigidity were treated with sedative and muscle relaxant as early as possible.

Formula I (chlorpromazine, meperidine and promethazine) was applicable to patients with a high fever and dysphoria. This formula is recommended to be used with caution in patients with respiratory failure and those younger than 1 year or older than 60 years old. Formula II (chlorpromazine, promethazine and hydergine) was used to treat patients in whom the hyperthermia was accompanied by respiratory dysfunction or tachycardia. Formula III (chlorpromazine, promethazine and procaine) was administered to patients with oliguria. This formula is recommended to be used with caution in patients with a slow heart rate or arrhythmia. Formula IV (chlorpromazine and promethazine) was administered to patients with relatively mild hyperthermia.

When selecting Formula I or II, it was necessary to consider the condition of the patient. A full or half dose was required to fully achieve the requirements at the first administration, with physical cooling applied half an hour after the administration of the sedative and muscle relaxant. The dose was sufficient if patients did not undergo shivering with skin reactions; if it was insufficient, additional medication was administered. After this treatment, the temperature gradually decreased. When the desired temperature was reached, the treatment was transferred to the maintenance phase. Ice application was reduced and alternative medication at a half to a third of the full dose was administered every 4-8 h. Formula II was generally used as an additional medication, since Formula I contained meperidine which could cause inhibition of respiration.
The duration of hypothermia was $3-12$ days, and rewarming was carried out every 2-3 days. The temperature was observed and therapeutic hypothermia was administered again if necessary; in addition, if inhibition of respiration occurred due to meperidine administration, the treatment was terminated. The duration of the hypothermia was extended until the edema had gone for patients with severe cerebral edema.

The rate of temperature lowering in adults was at $1-2^{\circ} \mathrm{C} / \mathrm{h}$, to the final temperature of $35-36^{\circ} \mathrm{C}$, while that of children was maintained at $2-3^{\circ} \mathrm{C} / \mathrm{h}$. Rapid cooling may cause shivering and increase oxygen consumption, which should be avoided. In certain cases, corticosteroids were used at an early stage to protect the blood-brain barrier. Short-range high-dose shock therapy was used, firstly with dexamethasone and methylprednisolone. The dose of methylprednisolone was $5 \mathrm{mg} / \mathrm{kg}$, repeated every $6 \mathrm{~h}$. The dose was decreased to $1 \mathrm{mg} / \mathrm{kg}$ after $24 \mathrm{~h}$ and maintained for three days. Intrathecal medications were given for hemorrhagic cerebrospinal fluid replacement once a day. Hemorrhagic cerebrospinal fluid was slowly replaced at a volume of 30-50 ml each time. The cerebrospinal fluid turned clear in approximately a week.

Statistical analysis. The Statistical Package for Social Sciences (SPSS, Inc., Chicago, IL, USA), version 16.0 was used for data analysis. Continuous variables are expressed as the mean \pm standard deviation, and categorical variables are expressed as proportions. Comparisons between continuous variables were performed using independent-samples t-test or variance analysis; comparisons between categorical variables were performed by the $\chi^{2}$ test. $\mathrm{P} \leq 0.05$ was considered to indicate a statistically significant result.

\section{Results}

Characteristics of the patients. A total of 110 patients were enrolled in the study, and the duration of hyperthermia ranged from 3 to 7 days. There were 42 cases with hyperthermia within $12 \mathrm{~h}$ after injury and 68 cases within $24 \mathrm{~h}$.

There were 73 cases with extensive cerebral contusion including serious brain tissue swelling with obliteration of the basal cisterns of the brain and fissures, 44 cases with multiple intracranial hematoma, 71 cases with brainstem contusion and hemorrhage, 26 cases with diffuse axonal injuries, 38 cases with herniation, 85 cases with subarachnoid hemorrhage and 90 cases with contrecoup injuries. In addition, there were 70 cases requiring emergency craniotomy and hematoma surgery, including 34 cases with unilateral craniotomy, 
Table II. ICP statistics of the two types of therapy.

\begin{tabular}{lccc}
\hline Groups & Cases & ICP prior to treatment $(\mathrm{mmHg})$ & ICP following treatment $(\mathrm{mmHg})$ \\
\hline Normothermia & 40 & $26.8 \pm 17.5$ & $12.3 \pm 8.5$ \\
Mild hypothermia & 40 & $27.5 \pm 16.9$ & $13.8 \pm 7.8$ \\
\hline
\end{tabular}

ICP, intracranial pressure.

Table III. Mortality of patients with different coma scores in the two groups.

\begin{tabular}{lccr}
\hline Initial GCS group & Mild hypothermia & Normothermia & $\chi^{2}$ \\
\hline All patients & $25(22.7)^{\mathrm{a}}$ & $39(35.5)$ & 4.319 \\
$\begin{array}{l}\text { Mortality, } \mathrm{n}(\%) \\
\text { Total, } \mathrm{n}\end{array}$ & 110 & 110 & 0.038 \\
Patients with coma scores of 3-5 & $18(40.9)^{\mathrm{a}}$ & $28(68.3)$ & 6.409 \\
Mortality, $\mathrm{n}(\%)$ & 44 & 41 & 0.011 \\
Total, $\mathrm{n}$ & & $11(15.9)$ & 0.831 \\
Patients with coma scores of 6-8 & $7(10.6)$ & 69 & 0.362 \\
Mortality, $\mathrm{n}(\%)$ & 66 & & \\
Total, $\mathrm{n}$ & & & \\
\hline
\end{tabular}

${ }^{\mathrm{a}} \mathrm{P}<0.05$ compared with normothermia. GCS, Glasgow Coma Scale.

35 cases with bilateral craniotomy, and one case with removal of a hematoma in three parts in three separate surgeries.

Outcomes. Of the 110 cases treated with mild hypothermia, 25 cases succumbed following a persistent fever of $>40^{\circ} \mathrm{C}$, and certain cases were accompanied by severe complications, including 12 cases with acute renal function failure, 5 cases with convulsions, 15 cases with gastrointestinal bleeding, 24 cases with severe pulmonary infection, 13 cases with high blood sugar and 4 cases with pseudomembranous enteritis. A total of 85 cases survived, including 13 cases of vegetative state, 12 cases with living disability and 60 cases that were restored to a good state of health. In the mild hypothermia group, the recovery rate was $54.5 \%$ and mortality rate was $22.7 \%$. The severe and mild disability rates were 11.8 and $10.9 \%$, respectively.

The GCS scores and ICP data of the hypothermia group showed no significant difference compared with those of the normothermia group, ( $>0.05$; Tables I and II). The mortality rates of the patients in the hypothermia group and normothermia group exhibited a significant difference $(\mathrm{P}=0.038$; Table III). The mortality rates of patients with GCS scores of between 3 and 5 revealed a statistically significant difference between the two groups ( $\mathrm{P}=0.011$; Table III). No significant difference was observed in the mortality rates of patients with GCS scores of between 6 and 8 between the two groups ( $\mathrm{P}>0.05$; Table III).

\section{Discussion}

During the clinical treatment, it was observed that simply using head ice caps and ice bags on the surface of large vessels, did not provide a satisfactory cooling effect. There were four reasons: Unreasonably placed ice bags or caps, a limited contact area and a gap between the cooling device and the skin resulted in insufficient heat conduction; patients in a lateral position had a reduced contact area with the ice blanket; the cold stimulation exacerbated blood capillary contraction, which decreased heat dissipation; and shivering caused by the cold increased the production of heat. Therefore, it was considered necessary to combine this treatment with other physical cooling treatments.

A sponge bath using tepid water mixed with alcohol was found to be a simple, safe and efficacious method. Not only could the alcohol and water stimulate the capillaries in the skin to dilate and increase the heat dissipation, but also evaporation was able to take heat away. This could be used as a rapid therapeutic method during the initial stage of stepwise cooling.

The sedative and muscle relaxant were administered to reduce cellular metabolism, block the acute stress response, control muscle spasms and shivering, prevent convulsions and expand peripheral vessels. The formulations used were unrestricted; however, it is recommended that the dose and rate of administration are strictly controlled. In the present study, three cases experienced a sudden drop in blood pressure due to the intravenous therapy being administered too rapidly. Due to the reduced heart rate and blood pressure, low body temperature and weak breathing, the medication was discontinued. No fatal complications such as cardiac arrhythmia were observed during the cooling process and the related nursing care was easy to carry out. With a lower mortality rate compared with that of normothermia therapy, the mild hypothermia therapy was demonstrated to be safe, convenient and efficacious. 
Short-range high-dose shock therapy with corticosteroids $(23,24)$ acts by stabilizing ion channels in the cell membrane and promoting the outward flow of $\mathrm{Ca}^{2+}$ ions, thereby reducing phosphate kinase activity and cell metabolism, which is conducive to the functional recovery of the temperature regulating center. However, it is necessary to pay attention to side-effects such as gastrointestinal bleeding $(25,26)$, glucose $(27)$ and nitrogen metabolism disorders (28) and immunosuppression (29).

The initiation and duration times of hypothermia remain controversial (5), due to the different types and severities of traumatic brain injury. A review of 13 clinical studies (30) found that treatment was started 6-22 $\mathrm{h}$ from onset and was maintained for an average of $40.9 \mathrm{~h}$ (range, 24-67 h). The mean duration in the present study was $>7$ days and the longest case had a duration of 12 days; this patient awoke from a coma 36 days after the injury and the brain function recovered well.

Formula II of sedative and muscle relaxants was found to be the optimum choice. Hydergine is able to expand blood vessels, has a relatively low inhibitory effect on the respiratory center and does not inhibit the adenosine triphosphate enzyme system, which is beneficial to further regulate metabolism disorders, ensure the effective circulating blood volume of the heart, brain and kidneys and facilitate the recovery of central nervous system functioning (31).

In conclusion, therapy using mild hypothermia associated with sedative and muscle relaxant was beneficial in reducing the mortality of patients with malignant hyperthermia following severe traumatic brain injury, particularly in patients with GSC scores of between 3 and 5 on admission. Due to the low incidence of complications and ease of nursing care, the mild hypothermia therapy was considered to be efficacious, safe and convenient. However, a retrospective study was used to explore the mild hypothermia therapy, without a randomized controlled trial. Prospective rigorous randomized clinical trials are required to provide evidence of the efficacy of "cool and quiet' therapy in the treatment of hyperthermia.

\section{References}

1. Li J and Jiang JY: Chinese Head Trauma Data Bank: effect of hyperthermia on the outcome of acute head trauma patients. J Neurotrauma 29: 96-100, 2012.

2. Ginsberg MD and Busto R: Combating hyperthermia in acute stroke: a significant clinical concern. Stroke 29: 529-534, 1998

3. Wang CX, Stroink A, Casto JM and Kattner K: Hyperthermia exacerbates ischaemic brain injury. Int J Stroke 4: 274-284, 2009

4. Cairns CJ and Andrews PJ: Management of hyperthermia in traumatic brain injury. Curr Opin Crit Care 8: 106-110, 2002.

5. Childs C, Wieloch T, Lecky F, Machin G, Harris B and Stocchetti N: Report of a consensus meeting on human brain temperature after severe traumatic brain injury: its measurement and management during pyrexia. Front Neurol 1: 146, 2010.

6. Jiang, JY, Gao GY, Li WP, et al: Early indicators of prognosis in 846 cases of severe traumatic brain injury. J Neurotrauma 19 869-874, 2002

7. Natale JE, Joseph JG, Helfaer MA and Shaffner DH: Early hyperthermia after traumatic brain injury in children: risk factors, influence on length of stay, and effect on short-term neurologic status. Crit Care Med 28: 2608-2615, 2000.

8. Tokutomi T, Morimoto K, Miyagi T, et al: Optimal temperature for the management of severe traumatic brain injury: effect of hypothermia on intracranial pressure, systemic and intracranial hemodynamics, and metabolism. Neurosurgery 52: 102-112, 2003.

9. Stiefel MF, Spiotta A, Gracias VH, et al: Reduced mortality rate in patients with severe traumatic brain injury treated with brain tissue oxygen monitoring. J Neurosurg 103: 805-811, 2005.
10. Dietrich WD and Bramlett HM: The evidence for hypothermia as a neuroprotectant in traumatic brain injury. Neurotherapeutics 7 : 43-50, 2010.

11. Yokobori S, Frantzen J, Bullock R, Gajavelli S, Burks S, Bramlett $\mathrm{H}$ and Dietrich WD: The use of hypothermia therapy in traumatic ischemic/reperfusional brain injury: review of the literatures. Ther Hypothermia Temp Manag 1: 185-192, 2011.

12. Globus MY, Alonso O, Dietrich WD, Busto R and Ginsberg MD: Glutamate release and free radical production following brain injury: effects of posttraumatic hypothermia. J Neurochem 65 : 1704-1711, 1995

13. Maeda T, Katayama Y, Kawamata $\mathrm{T}$ and Yamamoto T: Mechanisms of excitatory amino acid release in contused brain tissue: effects of hypothermia and in situ administration of $\mathrm{Co}^{2+}$ on extracellular levels of glutamate. J Neurotrauma 15: 655-664, 1998.

14. Mori K, Maeda M, Miyazaki M and Iwase H: Effects of mild (33 degrees C) and moderate (29 degrees C) hypothermia on cerebral blood flow and metabolism, lactate, and extracellular glutamate in experimental head injury. Neurol Res 20: 719-726, 1998.

15. Mitani A, Kadoya F and Kataoka K: Temperature dependence of hypoxia-induced calcium accumulation in gerbil hippocampal slices. Brain Res 562: 159-163, 1991.

16. Chatzipanteli K, Wada K, Busto R and Dietrich WD: Effects of moderate hypothermia on constitutive and inducible nitric oxide synthase activities after traumatic brain injury in the rat. J Neurochem 72: 2047-2052, 1999.

17. Sakamoto KI, Fujisawa H, Koizumi H, Tsuchida E, Ito H, Sadamitsu D and Maekawa T: Effects of mild hypothermia on nitric oxide synthesis following contusion trauma in the rat. J Neurotrauma 14: 349-353, 1997.

18. Choi HA, Badjatia N and Mayer SA: Hypothermia for acute brain injury - mechanisms and practical aspects. Nat Rev Neurol 8: 214-222, 2012.

19. Clifton GL, Miller ER, Choi SC, et al: Lack of effect of induction of hypothermia after acute brain injury. N Engl J Med 344: 556-563, 2001

20. Clifton MG, Valadka PA, Aisuku IP and Okonkwo DO: Future of rewarming in therapeutic hypothermia for traumatic brain injury: a personalized plan. Ther Hypothermia Temp Manag 1: 3-7, 2011.

21. Tokutomi T, Morimoto K, Miyagi T, Yamaguchi S, Ishikawa K and Shigemori M: Optimal temperature for the management of severe traumatic brain injury: effect of hypothermia on intracranial pressure, systemic and intracranial hemodynamics, and metabolism. Neurosurgery $52: 102-112,2003$.

22. Soukup J, Zauner A, Doppenberg EM, Menzel M, Gilman C, Young HF and Bullock R: The importance of brain temperature in patients after severe head injury: relationship to intracranial pressure, cerebral perfusion pressure, cerebral blood flow, and outcome. J Neurotrauma 19: 559-571, 2002.

23. Dearden NM, Gibson JS, McDowall DG, Gibson RM and Cameron MM: Effect of high-dose dexamethasone on outcome from severe head injury. J Neurosurg 64: 81-88, 1986.

24. Cooper PR, Moody S, Clark WK, Kirkpatrick J, Maravilla K, Gould AL and Drane W: Dexamethasone and severe head injury. A prospective double-blind study. J Neurosurg 51: 307-316, 1979.

25. Piek J, Chesnut RM, Marshall LF, et al: Extracranial complications of severe head injury. J Neurosurg 77: 901-907, 1992.

26. Halloran LG, Zfass AM, Gayle WE, Wheeler CB and Miller JD: Prevention of acute gastrointestinal complications after severe head injury: a controlled trial of cimetidine prophylaxis. Am J Surg 139: 44-48, 1980.

27. Jeremitsky E, Omert LA, Dunham CM, Wilberger J and Rodriguez A: The impact of hyperglycemia on patients with severe brain injury. J Trauma 58: 47-50, 2005

28. Clifton GL, Robertson CS, Grossman RG, Hodge S, Foltz R and Garza C: The metabolic response to severe head injury. J Neurosurg 60: 687-696, 1984.

29. Mayumi H, Zhang QW, Nakashima A, Masuda M, Kohno H, Kawachi Y and Yasui H: Synergistic immunosuppression caused by high-dose methylprednisolone and cardiopulmonary bypass. Ann Thorac Surg 63: 129-137, 1997.

30. Groysman LI, Emanuel BA, Kim-Tenser MA, Sung GY and Mack WJ: Therapeutic hypothermia in acute ischemic stroke. Neurosurg Focus 30: E17, 2011.

31. Geffroy A, Bronchard R, Merckx P, Seince PF, Faillot T, Albaladejo $P$ and Marty J: Severe traumatic head injury in adults: which patients are at risk of early hyperthermia? Intensive Care Med 30: 785-790, 2004 